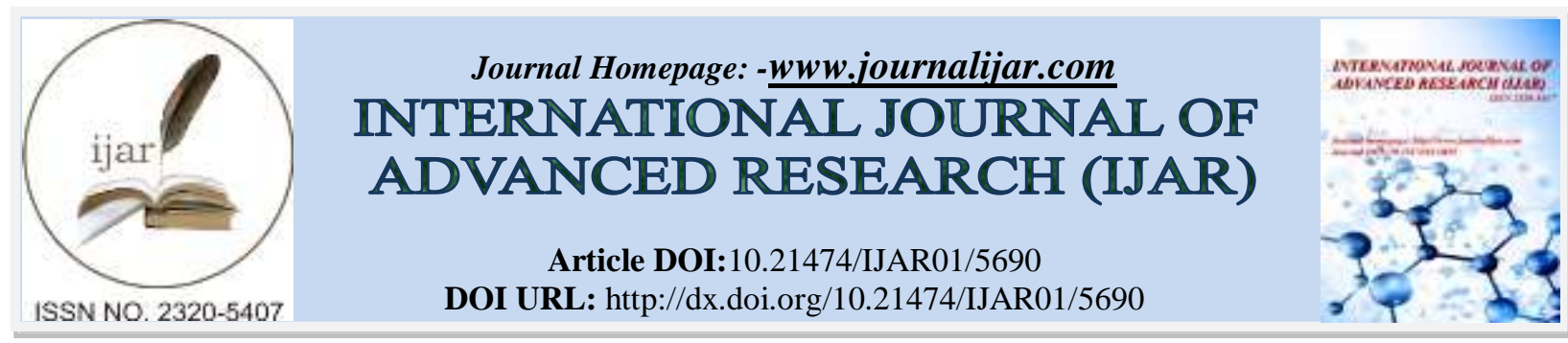

RESEARCH ARTICLE

\title{
GENETIC VARIABILITY OF THREE INDIGENOUS SUDANESE CATTLE BREEDS USING RAPD MOLECULAR MARKERS.
}

Fatima. Ali. ${ }^{1}$, Nawal. N. Omer ${ }^{2}$, Makkawi A. A ${ }^{3}$ and Ahmed S. $S^{3}$ and Nahid. Gornas ${ }^{4}$.

1. Faculty of Agriculture and Natural Resource/Kassala University/Sudan.

2. Ministry of Animal Resources, Fisheries and Rangland, Khartoum, Sudan.

3. Sudan University of Science and Technology, College of Graduate/Animal Production Department.

4. Department of Molecular Genetics, Central Laboratory, Ministry of Higher Education and Scientific Research, Khartoum, Sudan.

\section{Manuscript Info}

.........................

Manuscript History

Received: 22 August 2017

Final Accepted: 24 September 2017

Published: October 2017

Key words:-

Cattle, Rapd-Pcr, Sudan, Genetic Similarity, Genetic Distance

\section{Abstract}

This research was mainly to assess the genetic similarity and genetic distance ofthree indigenous Sudanese cattle breeds (Erashy, Butana and Kenana). Six arbitrary primers were used to detect DNA polymorphisms. Two hundred and twenty nine fragments were amplified. A high level of genetic variation was observed among and within population studied. Genetic distances between populations ranged from 0.59 to 0.64 . Results of phylogenetic analysis indicated that Erashy cattle breed is genetically closer to Butana cattle breed than to Kenana cattle breed. The study also concluded that such high level of genetic differentiation within Sudanese cattle populations leads to the speculation that they might belong to different breeds despite their having the same name and similar morphological traits. This study recommended that genetic characterization of these populations needs to be clarified in the future by more specific molecular techniques.

Copy Right, IJAR, 2017,. All rights reserved.

\section{Introduction:-}

Sudan is considered one of the countries with the largest livestock population in Africa and its climatic diversity resulted in a diversity in livestock with camels in the Northern belt ,cattle in western and southern belts, while sheep and goats are found all over the country, also the huge resources of fish and poultry. In spite of the fact that agricultural lands represent one third of the country area, only one third have been utilized. In addition, to various water resources including abundance in rain water which provides good opportunity for water harvesting. This guide to the conclusion that; Sudan has great livestock potentialities if the proper policies are formulated and implemented [1]. Indigenous cattle which were estimated by MOARFR [2] about 29.618 .000 heads, are considered the backbone of relevant and sustainable livestock production in Sudan because they are" compared to high performing exotic breeds" better adapted to harsh environments. Moreover, they require less input and management.

Characterization of local breeds is considered a major obstacle in Sudan, especially in areas of tribal contacts. Nomadic tribes own most of the animals, even in the large areas of South, few tribes lead a sedentary life [3].The large number of tribal breeds or strains in Sudan are mainly designated by external traits, specifically conformation and sometimes size and branding. The country is so large that obviously some of these groups of animals are separated geographically for a long time, justifying the assumption of lack of contact; thus, each breed must 
supposedly have a unique set of genes. It will be very useful if relative amount of variation between and within these populations could be identified [4]. A main prerequisite for the proper management ofAnimal Genetic Resources (An GR) is to identify and characterize the genetic resources and recognize the extent to which these breeds, strains and populations differ from each other. Thereafter, comes the talk about development, conservation and/or utilization of these breeds to the benefit of the country [5].

Local cattle breeds are considered, for many reasons, precious genetic resources that tend to disappear because of the new market and agricultural demands. Nevertheless, there is a serious risk that most of these breeds will disappear before they have been fully characterized and studied [6]. On the other hand, the usefulness of phenotypic traits to study the genetic variation between populations is very limited [7].

Classification using molecular markers provides a large unbiased basis for the estimates of average breed similarities and/or differences. To date alternative molecular markers are available to characterize cattle breeds, and the Random Amplified Polymorphic DNA (RAPD) method is one of them with relatively low cost, efficient and easy to apply widely. The number of loci that could be examined is essentially unlimited unlike other methods [8]. To lay the ground for further studies, this study was designed with the specific objective of assessing genetic variability among three indigenous Sudanese cattle breeds using RAPD markers.

\section{Material and Methods:-}

The present study was carried out at the Department of genetics, Central Laboratory, Ministry of Higher Education and Scientific Research, Sudan.

\section{Breeds included in the study:-}

Twenty-five (25) animals of each breed were sampled (Erashy, Kenana and Butana cattle breeds), from regions where each breed is predominantly found. Samples from the Erashy cattle type were obtained from the Aflamaiate village, north (Delta Elgash) province, Kassala State, Eastern of Sudan. Kenana cattle sampling was obtained from Um Banein Station situated on the western bank of the Blue Nile, about $360 \mathrm{~km}$ south of Khartoum, while samples of Butana cattle were obtained from the Atbara livestock research station,about $300 \mathrm{~km}$ north of Khartoum.

\section{Description of breeds included in the study:- Kenana:-}

Kenana cattle breed is one of the large East African Zebu and has several strains, named Rufáai El Hoi, Rufáai El Sherik, Fung, Gezira and White Nile. The breed is believed to have descended from the first zebu introduced to Africa from West Asia. This breed remained largely with semi-nomadic pastoralists in northern Sudan. They are distributed east of the confluence of the Blue and White Niles, south-east to the Ethiopian borders, and the western banks of the Blue Nile to southern Khartoum [9]. They are medium to large in size. Coat color is white or steel grey with darker shading on the neck and shoulders and a black switch to the tail, blue-grey to white with black shadings on the head, neck, hump, hindquarters and legs, horns are black. Calves are reddish-brown at birth turning grey by about six months of age[10]. They have well-developed dewlap commencing under the chin often as a double fold, and runs well back along the floor of the chest, frequently joining the large umbilical fold [11] . They also possess sheath. The udder is well developed. Horns are often lost; females have shorter horns than males [10].

\section{Butana:-}

It has descended from the first zebu introduction into Africa from West Asia. This breed remained largely with nomadic pastoralists (Batahin, Shukria), but Dongola and Shendi strains are kept by settled farmers. They inhabit the Butana plain in central Sudan, an Acacia scrub and desert area lying between the Blue Nile and Atbara River. Being originated in the Butana plain, east of the Blue Nile, have spread to Gezira in central Sudan and along the river Nile in the northern region. They are referred to as Dar El Reih cattle across the White Nile in the northern part of Darfur and Kordofan. It is also found in the northern area of Kassala state [12]. The predominant coat colors is red or dark red, the tongue, muzzle ,eyelids and around the coronet are black; light red with white may also exist [10]. Dewlap is well developed and runs down in front of the forelegs forming few folds [13], and is prominent in both sexes.

\section{Erashy cattle:-}

Erashy means the white cow in Beja local language [14] , [15], owned by Hadandawa tribe and known as the best milk breed in the area, and it is divided into two main sub-types coat color of Erashy cattle type was mainly white, 
other colors bright red brown and multi - color [16]. Almost all the animals were found to have black eyes, black to white eyelids and black eyelashes, tip hair was black and brown, and hoof was black and brown muzzle.

\section{DNA extraction and amplification:-}

Genomic DNA was extracted from whole blood and purified according to[17]. Six primers (Table,1) (OPC-01, OPC-02, OPC-05 , OPC-013, OPE,OPE-016, OPE-018 of Euro fins MWG/Operon Inc., CA, UK)were used, (Table 1) [18]. Amplification reaction was performed using a mixture having final concentration of $5 \mu \mathrm{l}$ of Master-mix (Maxim PCR PreMix $\times$ Kit $(i$-Taq); $1.5 \mu$ l of Primer, $1.5 \mu$ l of genomic DNA template.

Table, (1):- The base sequences of (10-mer) RAPD primers used for detected polymorphism within local breeds.

\begin{tabular}{|l|l|l|l|l|l|}
\hline $\begin{array}{l}\text { Primer } \\
\text { name }\end{array}$ & Sequence5' $\mathbf{\prime}^{\prime 3}$ & $\begin{array}{l}\text { GC- } \\
\text { Content }\end{array}$ & $\begin{array}{l}\text { Primer } \\
\text { name }\end{array}$ & Sequence5'-3 & $\begin{array}{l}\text { GC- } \\
\text { Content }\end{array}$ \\
\hline OPC-01 & TTCGAGCCAG & $60 \%$ & OPC-013 & AAGCCTCGTC & $27.6 \%$ \\
\hline OPC-02 & GTGAGGCGTAC & $70 \%$ & OPE-016 & CACACTCCAG(10) & $60 \%$ \\
\hline OPC-05 & GATGACCGCC & $70 \%$ & OPE-018 & TGAGTTGGGTG(10) & $60 \%$ \\
\hline
\end{tabular}

\section{Data scoring and analysis:-}

Only clearly distinguishable and reproducible bands were considered and data was entered in a computer file as a binary matrix " 0 " coded for absence and " 1 " for presence of a band. The genetic variability within and between populations were estimated based on the presence or absence of the bands within RAPD patterns. Genetic variability was calculated according to Nei and Li [19]. Analysis of RAPD patterns involved first combining the total number of bands for each animal and for all the primers. The number of bands common between each two breeds formed the basis of calculation of relatedness by the Dice algorithm [19].

Clustering for the result based on similarity matrix which was obtained with Unweighted Pair Group Method of Arithmetic Average (UPGMA) [20]and relationship within and between breeds was visualized as dendrogram displaying the hierarchical association among all genotypes. The Similarity Matrix contains all of the similarity values relating any two samples in the population. Pair wise comparison was made between genotypes, on basis of bands that showed polymorphism among all genotypes, and the values used to generateNei's genetic distances[19]. The Computations were performed using Person- Unweighted Pair Group Method with Arithmetic mean (UPGMA) software for data analysis.

\section{Results and Discussion:-}

\section{Primer screening andpolymorphic fragment:-}

All breeds showed variation with each other on their amplification profile (Table, 2). The total number of reproducible bands by the six primers reached two hundred and twenty nine (229) bands amplified. The number of bands amplified in all breeds ranged from 23 to 48 with a mean value of (38.17) bands per primer. The highest total amplified bands were observed in Butana cattle breed (94) and the lowest ones in Kenana cattle breed (56) were determined while, in Erashy cattle breed bands were observed (79). The maximum numbers of fragment bands (46, 48) were produced by the primer OPC-2and OPE- 13 with $100 \%$ polymorphism respectively while the minimum numbers of fragments (23) were produced by the primer OPC-16 with $100 \%$ polymorphism. The size of amplified fragments for the different primers ranged from $150 \mathrm{bp}$ to $1200 \mathrm{bp}$ as indicated by the molecular weight marker (100bp DNA ladder), with the majority of individuals exhibiting bands in the $500 \mathrm{bp}$. Primers used were found to have high polymorphism (Table 3). These results indicated that the level of DNA variation was high among the animals studied, and these findings agreed with many researchers as [21] revealed that the percentage of polymorphic loci was 80.49, 78.05, and 73.17\%, for Kivircik, Gökçeada, and Sakiz sheep breeds, respectively. Mahfouz [22], who analyzed Egyptian sheep breeds, reported that fifty six out of 57 total amplified fragments (98.25\%) were polymorphic loci, and the rest were Monomorphic. Khalidi [23] analyzed three ovine breeds in Tunisia total of 59 loci were amplified, out of which 47 (79.66\%) were polymorphic, andDevrim and Kaya [24] analyzed ninety-one animals for Turkish cattle breeds and eighteen random primers were screened. A total of 89 loci were amplified, out of these bands $78(87.6 \%)$ were polymorphic; also some of the primers gave no bands in some samples. The reason may have either been in low quality DNA or the animal could be homozygote recessive for these loci. However, Apostol [25] reported that such a case is practically impossible. In some cases, a particular primer pair may give band in one sex but not in the other. This might be interpreted as the primer is specific to one 
of the sex chromosomes. Some common bands in one breed may be specific to that breed, while some common bands in different breeds may be explicitly to a higher zoological rank.

Table (2):- List of six primers amplified and total number of fragments of each primer in three breeds of cattle

\begin{tabular}{|l|l|l|l|l|l|}
\hline No. & Primers & Erashy & Kenana & Butana & Total fragments per primer \\
\hline 1 & OPC-1 & 12 & 8 & 17 & 37 \\
\hline 2 & OPC-2 & 14 & 14 & 18 & 46 \\
\hline 3 & OPC-5 & 10 & 9 & 17 & 36 \\
\hline 4 & OPC-13 & 16 & 16 & 16 & 48 \\
\hline 5 & OPE-16 & 9 & - & 14 & 23 \\
\hline 6 & OPE-18 & 18 & 9 & 12 & 39 \\
\hline Total bands & & 79 & 56 & 94 & 229 \\
\hline
\end{tabular}

Table (3):- Number of bands generated and percentage polymorphism within cattle breeds as revealed by RAPD

\begin{tabular}{|l|l|l|l|l|l|l|l|l|l|l|l|l|l|l|}
\hline No & Primers & \multicolumn{3}{l|}{ Total bands } & \multicolumn{3}{l|}{ Monomorphic } & \multicolumn{3}{l|}{ Polymorphic } & \multicolumn{3}{l|}{ Polymorphism\% } \\
\hline & & $\mathrm{E}$ & $\mathrm{B}$ & $\mathrm{K}$ & $\mathrm{E}$ & $\mathrm{B}$ & $\mathrm{K}$ & $\mathrm{E}$ & $\mathrm{B}$ & $\mathrm{K}$ & $\mathrm{E}$ & $\mathrm{B}$ & $\mathrm{K}$ \\
\hline 1 & OPC-1 & 12 & 17 & 8 & 0 & 0 & 0 & 12 & 17 & 8 & 100 & 100 & 100 \\
\hline 2 & OPC-2 & 14 & 18 & 14 & 0 & 0 & 0 & 14 & 18 & 14 & 100 & 100 & 100 \\
\hline 3 & OPC-5 & 10 & 17 & 9 & 0 & 0 & 0 & 10 & 17 & 9 & 100 & 100 & 100 \\
\hline 4 & OPC-13 & 16 & 16 & 16 & 0 & 0 & 0 & 16 & 16 & 16 & 100 & 100 & 100 \\
\hline 5 & OPE-16 & 9 & 14 & - & 0 & 0 & 0 & 9 & 14 & - & 100 & 100 & - \\
\hline 6 & OPE-18 & 18 & 12 & 9 & 0 & 0 & 0 & 18 & 12 & 9 & 100 & 100 & 100 \\
\hline & Total & 79 & 94 & 56 & 0 & 0 & 0 & & & & & & \\
\hline
\end{tabular}

E=Erashy cattle breed $\quad \mathrm{B}=\mathrm{Butana}$ cattle breed $\mathrm{K}=$ Kenana cattle breed

\section{Genetic Variation and Phylogenetic:-}

Population studied showed variation on their amplification profile basis (Figure. 1, 2and 3). The genetic similarities matrix of RAPD was constructed according to Nei and Li [19] coefficient of similarities and distance as shown in table (4, 5 and 6). In this study RAPD technique using six primers for analysis revealed that the average level of polymorphism within, Erashy, Kenana and Butana were $81 \%, 78 \%$ and $73 \%$ respectively, and the DNA fragment size ranged from 150 to $1200 \mathrm{bp}$.High level of polymorphism within these local breeds were probably due to the reason that these cattle populations are owned by nomadic pastoralists or semi-nomads who move with their animals from one area to another in search of pasture and water. Consequently mating is more or less random and much genetic heterozygosity is expected. Within Erashy cattle the selected primers produced multiple bands (79bands). The number of bands amplified with these primers ranged from 9 to 18 and had a size range of 150 to $1000 \mathrm{bp}$ (Table 3and Fig.24). Maximum bands number was obtained with the primers OPE-18, while, the lowest number (9bands) was obtained withPOE-16.

Results reported here indicated that the high polymorphism within Erashy cattle type may be due to crossing Erashy cattle type with other breeds specially Eritrean due to many reasons such as the crop guarding committee could easily capture Erashy due to its calmness this lead Erashy owners to cross it with aggressive Eritrean breeds, also the drought which attack the area led the Erashy owners to cull all the bulls to reduce the cost of feeding, the prohibition of the animal from entering Elgash scheme for 10 months a very year cause the Erashy owners to graze inside the Eritrean areas which enhance crossing with other breeds as reported by Elhag [15]. High polymorphism obtained within Kenana (78\%)and Butana cattle in this study was more than that reported by Salah-Eldein [18], who revealed that the average level of polymorphism by RAPD marker using 10 primers selected for analysis, within western Baggara (Nialawy), Nilotic ( Majock), Butana and Kenana cattle were 22.9\%, 36.8\%, 24.4\% and $41.3 \%$ respectively. High polymorphism detected in the populations included in this study may be due to the different locations of sampling distributed in large geographical area of Sudan, also the nomadic system which enhances mating with other breeds. The genetic relationship among population was studied using cluster analysis based on similarity matrices using UPGMA from RAPD data. Cluster analysis (Figure4), of this current study concluded that the genetic relationship between Erashy and Butana cattle breed is closer than Kenana cattle. These results confirm previous data based on some morphological characters as reported by Maule [10]andOsman[14], which have shown that Erashy and Butana cattle breeds are similar. Historically pastoral cattle keepers traverse long distances across borders along with their cattle in search of more conducive environments for 
themselves and their cattle. During these movements there could be possibility for exchange of (genetic material) to allow gene flow from one population to another [18] and [26]. The phylogenetic trees constructed using UPGMA program based on RAPD genetic distance values presented in figure (1, 2 and 3) showed relationships within the three local breeds. It appears there has been extensive gene flow within these cattle breeds and that indicates the heterozygosity of Sudanese cattle. In conclusion, the results of this study indicated the effectiveness of RAPD markers in detecting the polymorphism and estimating genetic distance among Sudanese native cattle breeds, and also the RAPD markers provide a potential tool for studying within and between breeds genetic variability and for establishing genetic relationships. Approaches employing several DNA marker systems would increase the accuracy of genetic studies in local animal breeds and species.

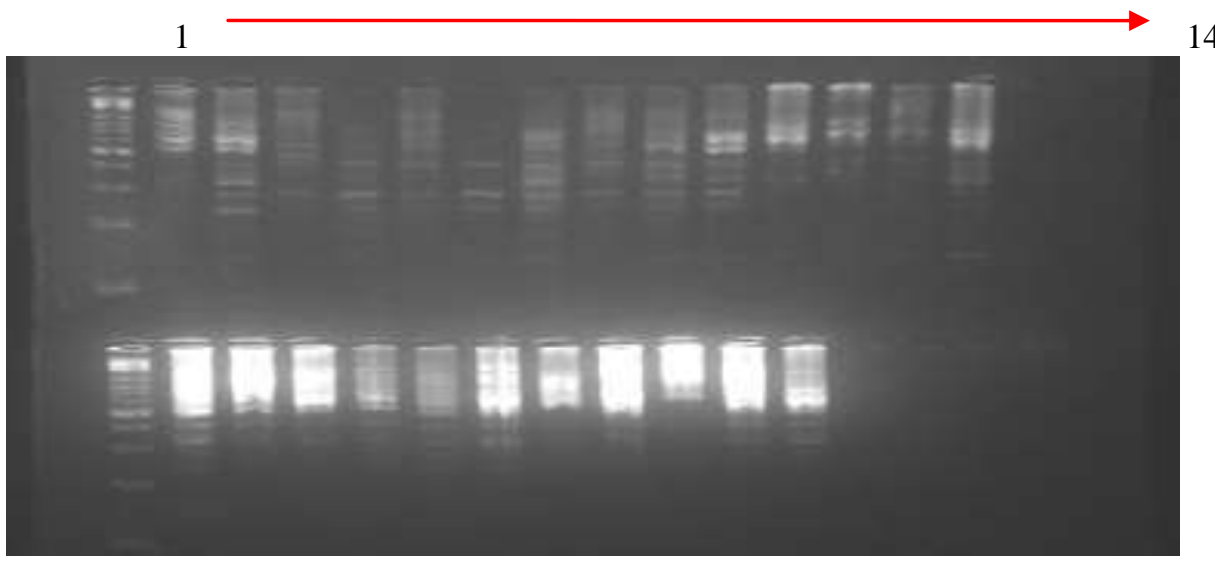

Fig: 1a

M

1 14

M

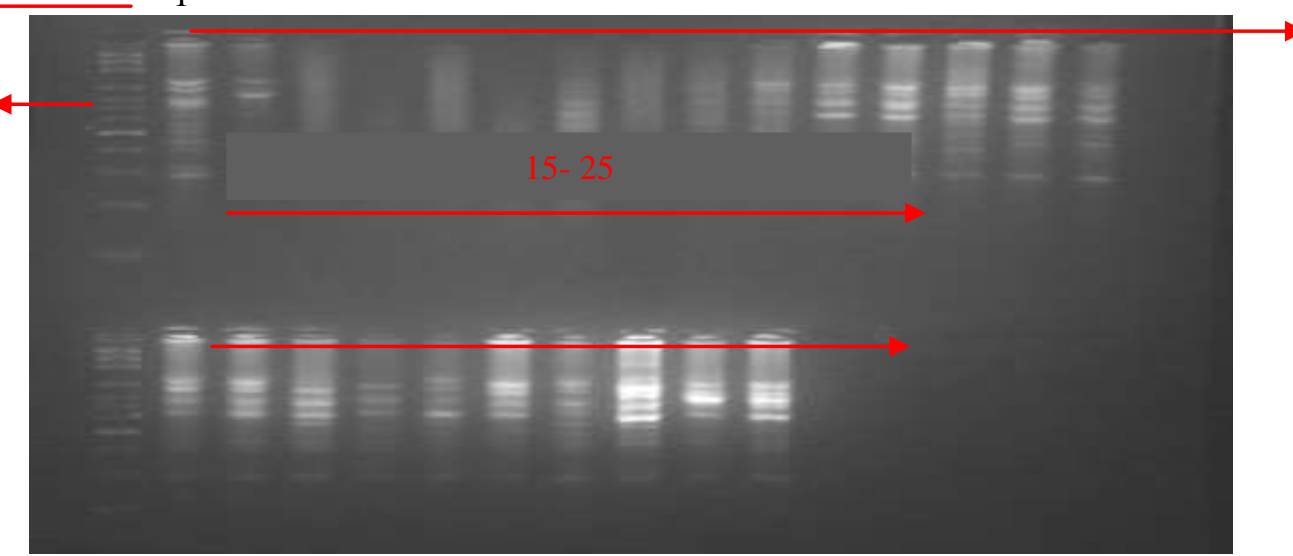

Fig:- $1 b$

Fig.1:- RAPD polymorphism identify with Erashy cattle breed (1.5\% agrosegel). Amplification with primer OPC2,(Fig 1a) and OPC1(fig1b).

M: molecular size marker 100bp ladder. 


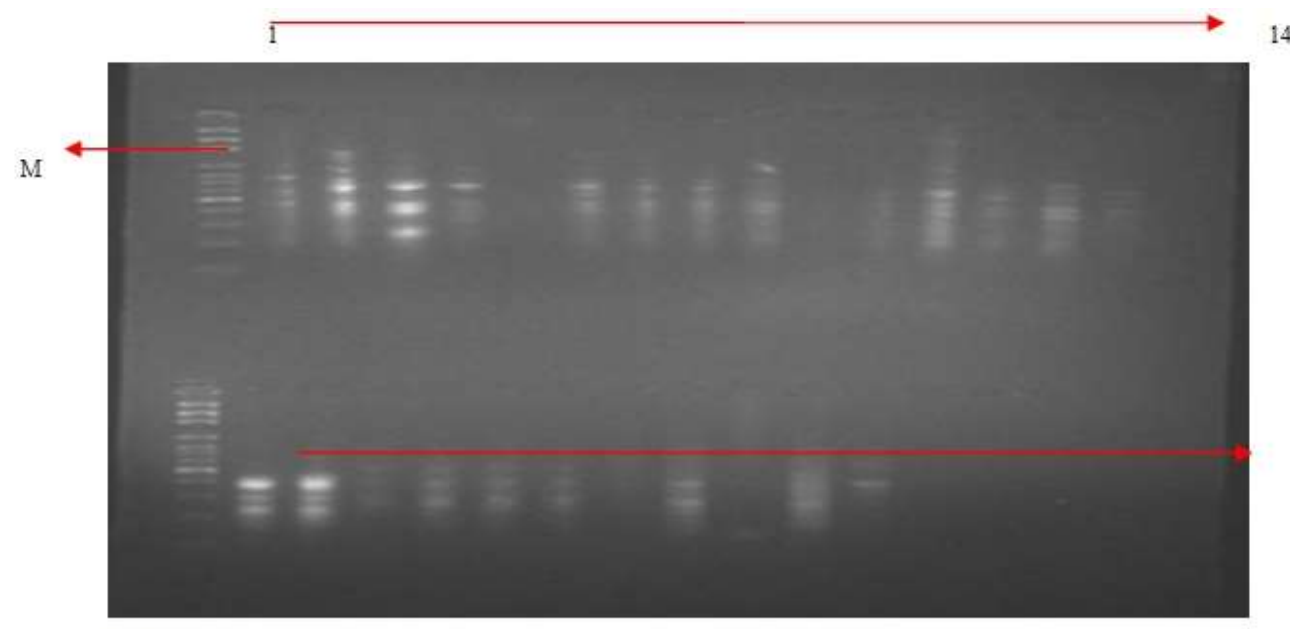

Fig: 2a

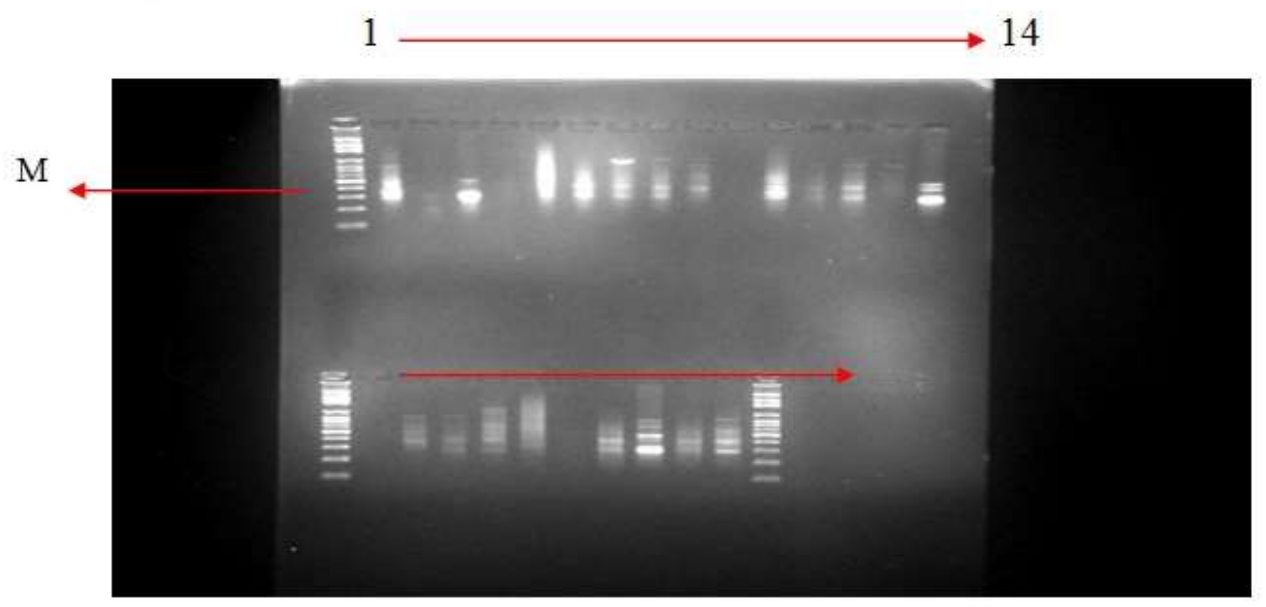

Fig: 2b

Fig.2 :- RAPD polymorphism identify with Kenana cattle breed (1.5\% agrose gel). Amplification with primer OPC13,(Fig 2a) and OPC-1(fig2).

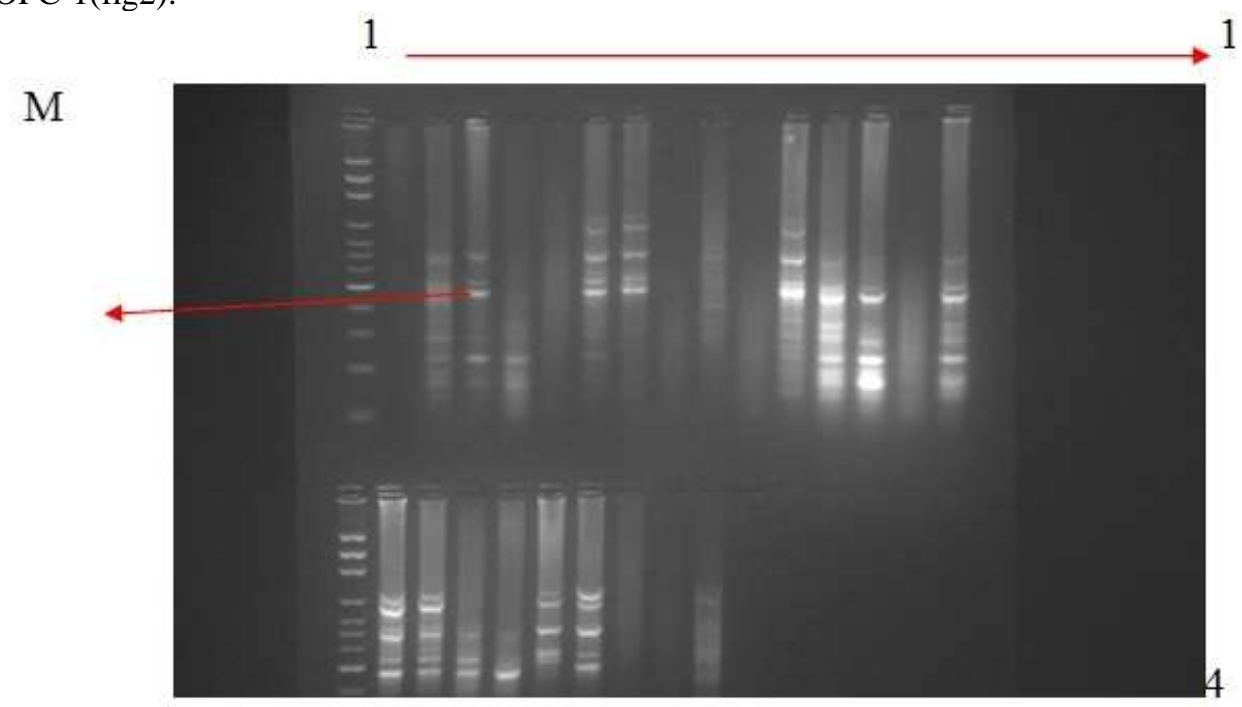

Fig: 3a 


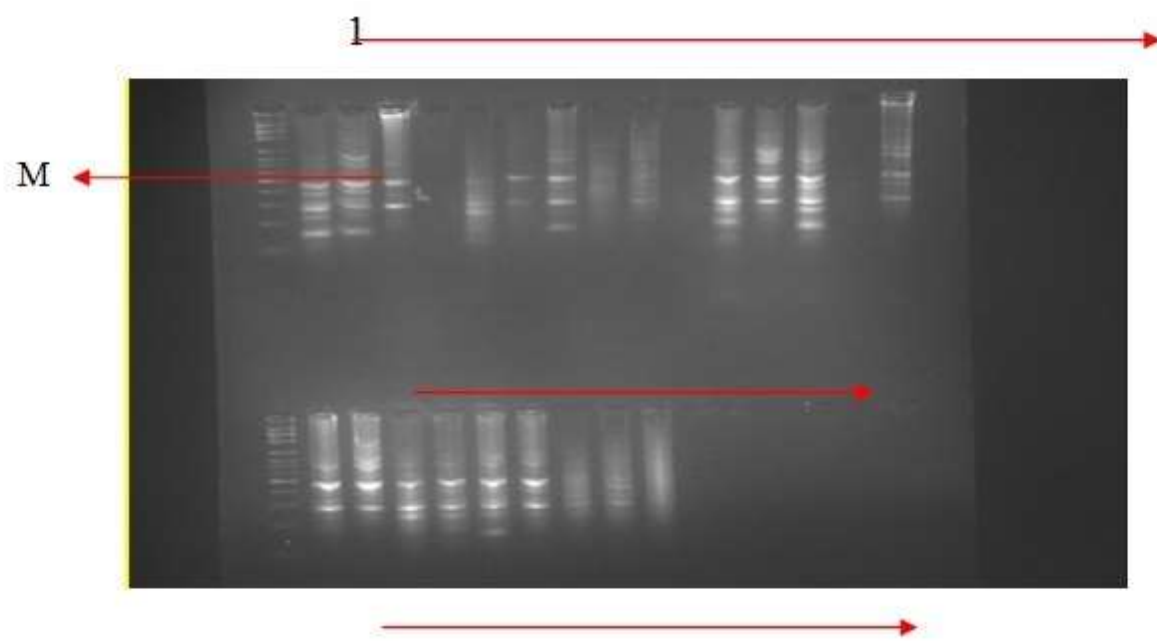

M: molecular size marker 100bp ladder.

Fig 3 b:-Fig.3RAPD polymorphism identify with Butana cattle breed (1.5\% agrosegel). Amplification with primer OPC-5,(Fig 3a) and OPE-18(fig3b). M: molecular size marker 100bp ladder.)

Table 4:- Average pair wise Genetic distance matrix among the indigenous Sudanese cattle breeds, computed according to Nei and Li (1979) similarity coefficient obtaining from RAPD Markers data.

\begin{tabular}{|l|l|l|l|}
\hline Breeds & Erashy & Kenana & Butana \\
\hline Erashy & 100 & & \\
\hline Kenana & 0.59 & 100 & \\
\hline Butana & 0.63 & 0.64 & 100 \\
\hline
\end{tabular}

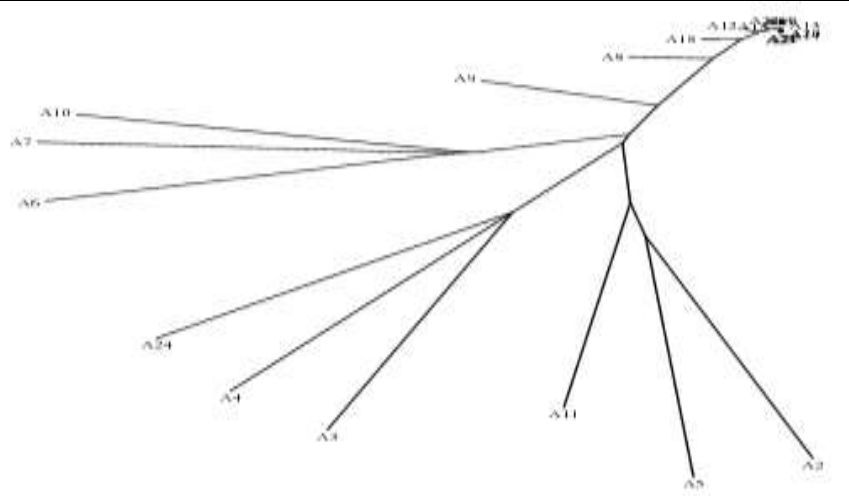

Dendrogram showing relationship within 25 individuals of Erashy cattle breed generated by UPGMA method based on RAPD analysis

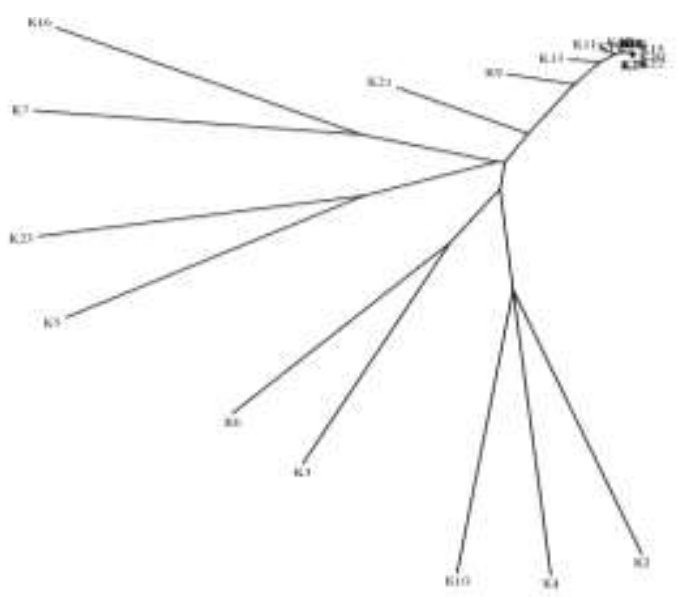


Dendrogram showing relationship within 25 individuals of Kenana cattle breed generated by UPGMA method based on RAPD analysis

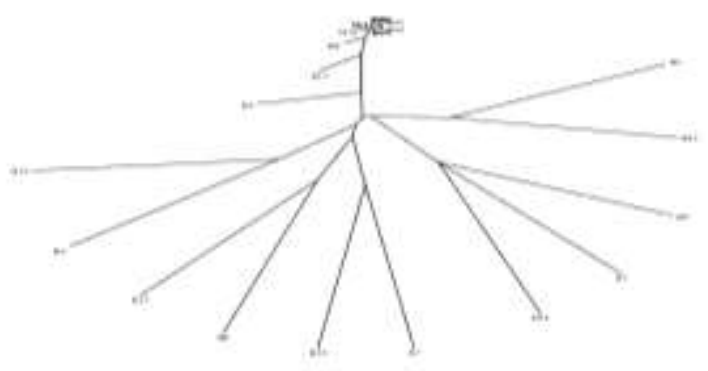

Dendrogram showing relationship within 25 individuals of Butana cattle breed generated by UPGMA method based on RAPD analysisB=Butana

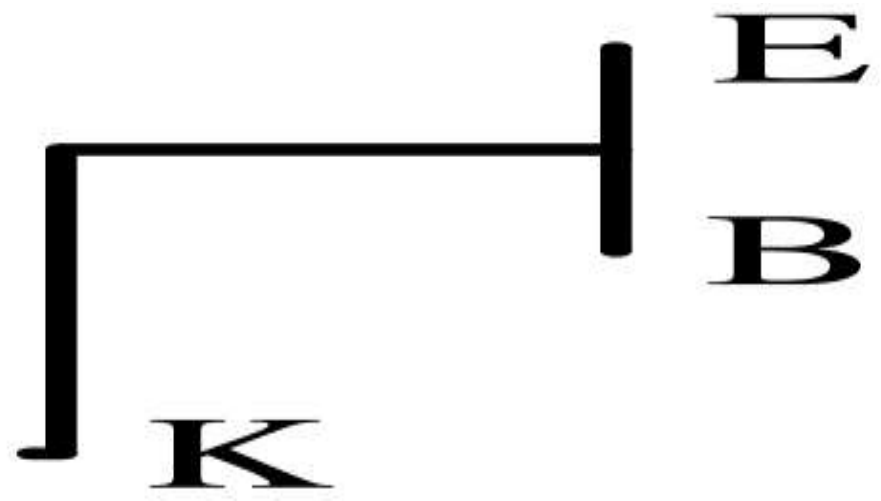

Dendrogram showing genetic relatedness among three indigenous Sudanese cattle breeds (Erashy, Butana and Kenana) based on RAPD data constructed by un weighted pair-group method using arithmetic averages (UPGMA). Where E, Band K represents Erashy, Butana and Kenana cattle breed respectively.

\section{Acknowledgments:-}

Authors would like to thank all technicians in the department of Molecular Genetics, central laboratory, Ministry of Higher Education and scientific research. This work was financially supported by University of Kassala, Sudan.

\section{References:-}

1. Ahmed, N. (2013). Livestock Future Perspective in Sudan: Imports threaten national producers and siphon foreign currency .news. Sudanvisiondaily.com.

2. Ministry of Animal Racecourses, Fisheries and Rangeland "MOARFR" (2013).

3. Payne, W.J.A. and Elamin, F.M. (1977). An interim report on the livestock industry in the Jonglei canal area. Khartoum, JEO, 1:1-125.

4. Nei ,M. and Takezaki,N. (1996). Reconstruction of phylogenetic trees from microsatellite (STR) loci . Animal Genetics, 27:(Suppl.2):1-3.

5. Cunningham, E.P, (1992). Animal genetic resources. Proc. Of the Workshop held at ILCA, Adis Ababa, Ethiopia.

6. FAO. Food and Agriculture Organization of the United Nations.( 2000). World watch list for domestic animal diversity. 3rd Edition. FAO, Rome, Italy.).

7. Meghan, C., Machugh, D.E., Bradley, D.G., (1994). Genetic characteristics of West African cattle . World Anim. Rev. 78: 59- 66.

8. Lynch, M., Milligan, B.G., (1994). Analysis of population genetic structure with RAPD markers. Mole. Ecol. 3: 91-99.

9. Saeed, A. M., Ward, P. N., Light, D., Durkin, J. W and Wilson, R. T.,(1987). Characterization of Kenana cattle at Um Banein, Sudan. ILCA Research Report 16. ILCA, Addis Ababa, Ethiopia. 46 pp.

10. Maule, J.P., (1990). The cattle of the tropics. Centre for Tropical Veterinary Medicine, University of Edinburgh, Great Britain. 225 pp. 
11. Epstein, H.E. (1971). The origin of the domestic animals of Africa. Volume I. Africana Publishing Corporation, New York, USA. 573.

12. Meddani, M. A. E., (1996). Animal Wealth and animal production in the Sudan. Pub. University of Khartoum.

13. Mason, I.L. and J.P. Maule, (1960). The indigenous livestock of Eastern and South Africa. Common wealth Bureau for Animal breeding and genetics. Tech Common. No. 14. Famhamroyal,Common wealth Agricultural Bureaux, UK.

14. Osman, N. Mohammed., (1998). Impediments to investment and development strategy for the livestock resources in eastern states, Sudan. PhD thesis. University of Gezira. Agri. College.

15. El-hag, M.H.M, (2004). Characterization of dairy production and Erashy breed

16. inElgash area .M.Sc. thesis. Faculty of Agric. Dept. of animal sci . Khartoum University.

17. Ali, F.M. I.,(2013).Phenotypic and Genotypic Characterization of Erashy Cattle Type in El- Gash Area (Kassala State - Sudan) PhD thesis Sudan University of Sciences and Technology. College of Graduate Studies.

18. Maniatis, T., Fritsch, E. F., and Sambrook, J. (1989).Molecular cloning: A laboratory manual .Cold spring Harbor laboratory .Cold spring Harbor NY, volume 2.

19. Salah Eldein, S.A., (2005). Estimation of genetic diversity in some Sudanese (Autochthonous) cattle using DNA markers. PhD thesis. Sudan University of Science and Technology College of A graduate Studies.

20. Nei, M, and W. H. Li., (1979). Mathematical model for studying genetic variation in terms of restriction endo nucleases. Proceedings of the National Academy of Sciences (United States of America) 76: 5269 - 5273.

21. Day.William, H.E; Edelsbrunner, Herbert (1984): Efficient algorithms for agglomerative hierarchical clustering methods. Journal of classification 1(1): 7-24. Doi: 10.1007/BF01890115. ISSN 0176-4268.

22. Elmaci, C., Y. Oner, S. Ozis, and E. Tuncel, (2007). RAPD analysis of DNA polymorphism in Turkish sheep breeds. Biochem. Genet. Oct; 45(9- 10):691-6. Epub, Sep 19.

23. Mahfouz, E. R., Othman, E. Othman., Soheir, M. El Nahas., and Mohamed A.A. El Barody. (2008). Genetic variation between some Egyptian sheep breeds using RAPD-PCR Research. Journal of Cell and Molecular Biology, 2(2): 46- 52.

24. Khalidi, Z., Rekik, B., Haddad, B., Zourgui, L., andSouid, S. (2009). Genetic characterization of three ovine breeds in Tunisia using randomly amplified polymorphic DNA markers. Livestock Research for rural Development 22(3).

25. Devrim A.K., Kaya N.(2004) : Genetic Polymorphism and Microsatellites. Kafkas Univ. Vet. Med. J. 10: 215220.

26. Apostol, B.L., Black, W.C., and Reiter, P. Miller, B.R. (1996).Population genetics with RAPD-PCR markers: the breeding structure of Aedesaegypti in Puerto Rico. Heredity, 76: 325-334.

27. Hassen, F., Bekele, E., Ayalew, W., andDessie, T. (2007). Genetic variability of five Indigenous Ethiopian cattle breeds using RAPD markers. African Journal of Biotechnology 6: 2274-2279. 